\title{
Management and Clinico-Pathologic Aspects of Non-Melanoma Skin Cancer of the Head and Neck: A Retrospective Institutional Based Study at the Egyptian National Cancer Institute
}

\author{
Ihab Samy Fayek ${ }^{1 *}$, Mohammed Ahmed Rifaat ${ }^{1}$, Dalia Bilal Mohammed ${ }^{2}$ \\ ${ }^{1}$ Surgical Oncology Department, National Cancer Institute, Cairo University, Egypt \\ ${ }^{2}$ Epidemiology and Statistics Department, National Cancer Institute, Cairo University, Egypt \\ Email: *drihab74@cu.edu.eg
}

How to cite this paper: Fayek, I.S., Rifaat, M.A. and Mohammed, D.B. (2019) Management and Clinico-Pathologic Aspects of Non-Melanoma Skin Cancer of the Head and Neck: A Retrospective Institutional Based Study at the Egyptian National Cancer Institute. Journal of Cancer Therapy, 10, 846-862.

https://doi.org/10.4236/jct.2019.1010072

Received: October 1, 2019

Accepted: October 20, 2019

Published: October 23, 2019

Copyright $\odot 2019$ by author(s) and Scientific Research Publishing Inc. This work is licensed under the Creative Commons Attribution International License (CC BY 4.0).

http://creativecommons.org/licenses/by/4.0/

c. (i) Open Access

\begin{abstract}
Background: Reviewing and analyzing the Clinico-pathologic aspects of non-melanoma skin cancer of the head and neck (NMSCHN), type of management, prognostic factors, and disease-free survival (DFS) in a period of 5 years at the National Cancer Institute-Cairo University-Egypt. Materials and Methods: A retrospective study of two hundred patients with NMSCHN was treated at the National Cancer Institute-Cairo University-Egypt from January 2008 to December 2012. The mean follow-up was 6 months (1- 84 months). Results: 117 males and 83 females with $90 \% \geq 50$ years old. The scalp (27.5\%), the periorbital region (13\%), the cheek (12.5\%) and the nose (12.5\%) are the main anatomical sites affected. BCC represented $71.5 \%$ with nodular type (79\%) predominance; SCC represented 21\% with GII (61.1\%) the commonest grade. Surgery was the main modality of treatment (93\%) with local flaps only (63.9\%) and primary closure (14.7\%) were the main surgical options following wide local excision. Positive and close margins were detected in $23.5 \%$ of excised specimens. No significant association was found between disease-free survival (DFS) and pathology, treatment modality, the occurrence of complications or safety margin status. Conclusion: NMSCHN lesions should be surgically excised in specialized high volume centers with readily available peripheral margin control and should be operated by senior experienced surgeons.
\end{abstract}

\section{Keywords}

Basal Cell Carcinoma, Squamous Cell Carcinoma, Non-Melanoma Skin Cancer 


\section{Introduction}

Non-melanoma skin cancer (NMSC) is the most common malignancy among Caucasians. NMSC principally comprises basal cell carcinoma (BCC) and squamous cell carcinoma (SCC), but includes a host of rarer skin tumors [1]. According to The National Cancer Registry in Egypt based on Data of 40,477 patients collected from Tanta Cancer Center retrospectively to form the largest population-based cancer registry in Egypt covering a period of 9 years, skin cancer incidence was calculated as $3.1 \%$ of all cancers in both sexes and $3.8 \%$ of all cancers in males based on population of Gharbia (as an indicator for rates in Egypt) and based on number of cases of each cancer type there [2]. In the Egyptian population, over $60 \%$ of NMSC could be attributed to sun exposure and approximately $45 \%$ to skin color [3]. More specifically the incidence of NMSC was addressed at the National Population-Based Cancer Registry Program (2008-2011) as 1.35\% of all cancers in males and $1.24 \%$ of all cancers in females [4]. In settings such as developing countries where Moh's Micrographic Surgery is not readily available, prediction of NMSC aggressive lesions based on preoperative information (age, immunosuppression status, and location) is critical not only for surgical planning but also for reducing recurrence risk by treating the lesion with sufficiently adequate margins. Several studies have attempted to create a risk scale or model for assessing preoperative risk for aggressive NMSCs [5] [6] [7] [8]. In Egypt, few studies focused on NMSC, mostly with a limited number of patients and not specific to NMSCHN and not addressing many prognostic factors highlighted and evaluated in this study [9] [10] [11] [12]. In other parts of the world, with almost similar climate to Egypt, skin cancer is a common cancer [13], with increasing incidence of SCC and Basosquamous carcinoma (BSC) [14]. This study will focus on Egyptian patients with non-melanoma skin cancer of the head and neck (NMSCHN) who presented, diagnosed and managed at the National Cancer Institute-Cairo University-Egypt.

\section{Materials and Methods}

A retrospective study where all patients' data with non-melanoma skin cancer of the head and neck (NMSCHN) diagnosed, admitted and managed at the National Cancer Institute-Cairo University-Egypt in the period from January 2008 to December 2012 were documented and analyzed regarding patients' characteristics (age and sex), tumor characteristics (anatomical site, $\mathrm{T}$ stage and number of lesions), histopathology (type and grade), treatment modality (surgery \pm adjuvant treatment or no interference), safety margin status (positive, close or negative), type of reconstruction and type of flap used, complications and recurrence(s) during a follow-up period ranging from 1 to 84 months with a mean follow-up of 6 months. Recurrence and Disease-free survival will be correlated statistically with different parameters.

\subsection{Exclusion Criteria}

- Patients with NMSCHN who were managed outside our institute and were 
just referred for follow-up or for consultation.

- Patients with Xeroderma pigmentosum.

- Patients with melanoma skin cancer by histopathology.

\subsection{Statistical Method}

Demographic data and survival outcome will be analyzed using SPSS statistical package version 20. Relations between qualitative data will be done using Chi-square test or Fisher's exact test. Moreover, survival analyses will be done using Kaplan Meier's method and Comparison between survival curves will be done using log-rank test. A p-value less than 0.05 will be considered significant.

\section{Results}

Two hundred patients with NMSCHN were involved in this retrospective study in the period from January 2008 to December 2012.

\subsection{Patients' Characteristics}

- Age: The age of the patients ranged between 5 and 90 years with the peak incidence in the sixth decade of life. $15.5 \%$ of patients were below or equal to the age of 50 while $84.5 \%$ were 51 years old or more (Table 1 ).

- Sex: Male patients constituted 58.5\% (117/200) of cases while females constituted $41.5 \%$ (83/200). Male to female ratio was about 1.4:1 (Table 2).

\subsection{Tumor Characteristics}

- Anatomical distribution of lesions: The main site affected was the scalp $27.5 \%$ (55/200), followed by the periorbital region $13 \%$ (26/200), while the cheek and nose were equally affected $12.5 \%(25 / 200)$ each. Two patients with BCC showed multiple lesions in different sites 1\% (2/200) (Table 3).

- T Stage: The majority of cases were $\mathrm{T} 1$ representing $52 \%$ of all cases (104/200) and T4 representing 4\% (8/200) with tumor invasion to parotid gland and eye globe (Table 4).

Table 1. Age distribution of patients with NMSCHN.

\begin{tabular}{ccc}
\hline Age (years) & Number of patients & Percent (\%) \\
\hline 50 & 31 & 15.5 \\
$>50$ & 169 & 84.5 \\
Total & 200 & 100 \\
\hline
\end{tabular}

Table 2. Sex distribution of patients with NMSCHN.

\begin{tabular}{ccc}
\hline Gender & Number of patients & Percent (\%) \\
\hline Males & 117 & 58.5 \\
Females & 83 & 41.5 \\
Total & 200 & 100 \\
\hline
\end{tabular}


Table 3. Anatomical site distribution of NMSCHN lesions.

\begin{tabular}{ccc}
\hline Site & Number of patients & Percent (\%) \\
\hline Scalp & 55 & 27.5 \\
Cheek & 25 & 12.5 \\
Auricle & 6 & 3 \\
Periorbital & 26 & 13 \\
Forehead & 10 & 5 \\
Upper lip & 11 & 5.5 \\
Lower lip & 20 & 10 \\
Nose & 25 & 12.5 \\
Neck & 2 & 1 \\
Nasolabial & 4 & 2 \\
Temple & 6 & 3 \\
Post-auricular & 4 & 2 \\
Pre-auricular & 4 & 2 \\
Post auricular, scalp, nose & 1 & 0.5 \\
Forehead, nasolabial, lower lip & 200 & 0.5 \\
Total & & 100 \\
\hline
\end{tabular}

Table 4. Distribution of NMSCHN lesions according to T stage.

\begin{tabular}{ccc}
\hline Stage & Number of patients & Percent (\%) \\
\hline T1 & 104 & 52 \\
T2 & 72 & 36 \\
T3 & 16 & 8 \\
T4 & 8 & 4 \\
Total & 200 & 100 \\
\hline
\end{tabular}

- Number of Lesions: $94 \%$ (188/200) of patients presented with a single lesion, $1 \%(2 / 200)$ of patients presented with 2 lesions and 5\% (10/200) with multiple lesions. 12 patients presented with two and more lesions where 8 of them BCC (two of them in different sites), 2 SCC and 2 were BSCC patients (Table 5).

\subsection{Tumor Histopathology: (Tables 6-8)}

All lesions were pathologically examined preoperatively and postoperatively to confirm the diagnosis and determine the margin status. BCC was detected in $72.5 \%(145 / 200)$ of patients, SCC in and basosquamous were detected in $21 \%$ $(42 / 200)$ and $6 \%(12 / 200)$ of patients, respectively (Table 6$)$. The most common type of BCC was the nodular type representing 79\% (113/200) of cases (Table 7). The most common grade among the fifty four patients with Squamous Cell Car- 
cinoma (SCC) and Basosquamous Carcinoma (BSC) was grade II, moderately differentiated tumors represented $61.1 \%$ (33/54) of cases (Table 8).

Table 5. Distribution of patients with NMSCHN according to the number of Lesions per patient.

\begin{tabular}{ccc}
\hline Number of lesions per patient & Number of patients & Percent (\%) \\
\hline Single & 188 & 94 \\
Two lesions & 2 & 1 \\
Three or more & 10 & 5 \\
Total & 200 & 100 \\
\hline
\end{tabular}

Table 6. Tumor histopathology of NMSCHN among the study population.

\begin{tabular}{ccc}
\hline Tumor Histopathology & Number of patients & Percent (\%) \\
\hline Basal cell carcinoma & 143 & 71.5 \\
Squamous cell carcinoma & 42 & 21 \\
Basosquamous & 12 & 6 \\
Adenocarcinoma & 3 & 1.5 \\
Total & 200 & 100 \\
\hline
\end{tabular}

Table 7. Clinico-pathologic types of BCC.

\begin{tabular}{ccc}
\hline Clinico-pathologic types & Number of patients & Percent (\%) \\
\hline Nodular & 113 & 79 \\
Adenocystic & 6 & 4.2 \\
Superficial spreading & 3 & 2.1 \\
Pigmented & 6 & 4.2 \\
Morpheaform & 6 & 4.2 \\
Micronodular & 1 & 1.4 \\
Infiltrative & 3 & 2.1 \\
Keratotic & 4 & 2.8 \\
Mixed nodular superficial & 1 & 0.7 \\
Total & 143 & 100 \\
\hline
\end{tabular}

Table 8. Histopathological Grades of Squamous Cell Carcinoma (SCC) and Basosquamous Carcinoma (BSC).

\begin{tabular}{ccc}
\hline Grade & Number of patients & Percent (\%) \\
\hline I & 14 & 25.9 \\
II & 33 & 61.1 \\
III & 7 & 12.9 \\
Total & 54 & 100 \\
\hline
\end{tabular}




\subsection{Treatment Modality: (Table 9)}

Surgery was the only treatment modality in $93 \%(186 / 200)$ of patients, surgery followed by post-operative radiotherapy (PORT) in $2 \%(4 / 200)$ of patients, they had positive margins and were not candidates for re-excision because of reconstruction and proximity to the eye. One patient (0.5\%) developed metastatic SCC and received adjuvant chemotherapy $3 \%$ (6/200) of patients developed local recurrence followed by lung metastasis they underwent surgical excision followed by radiotherapy then chemotherapy. Meanwhile, 3 patients with BCC (1.5\%) received no treatment because they were locally advanced, elderly with co-morbidities and beyond treatment.

\subsection{Safety Margin Status: (Table 10)}

Peripheral margin control guided by intraoperative frozen section analysis (IFSA) was not used in all patients but most of them. Postoperative Histopathological examination of all surgically excised specimens was done (except for four patients where SM was not assigned) for histopathological confirmation of tumor type and to detect adequacy of the safety margins where all specimens' margins were oriented by sutures. Margins of surgical excision were negative in $150(76.5 \%)$, positive in $41(20.9 \%)$ and close in $5(2.6 \%)$ of postoperative specimens.

\subsection{Closure of the Defect and Type of Reconstruction:}

\section{(Table 11 \& Table 12)}

Most of the study population underwent reconstruction with local flaps only $126 / 197$ (63.9\%), in $14.7 \%$ of patients (29/197) primary closure only was successfully achieved. Among patients who underwent surgical excision the method

Table 9. Treatment modality in patients with NMSCHN.

\begin{tabular}{ccc}
\hline Treatment Modality & Number of patients & Percent (\%) \\
\hline Surgery & 186 & 93 \\
Surgery + PORT & 4 & 2 \\
Surgery + chemotherapy & 1 & 0.5 \\
All & 6 & 3 \\
No interference & 3 & 1.5 \\
Total & 200 & 100 \\
\hline
\end{tabular}

Table 10. Safety margin status in postoperative pathologically examined specimens.

\begin{tabular}{ccc}
\hline Margin Status & Number of patients & Percent (\%) \\
\hline Positive & 41 & 20.9 \\
Close & 5 & 2.6 \\
Negative & 150 & 76.5 \\
Total & 196 & 100 \\
\hline
\end{tabular}


of defect closure was not assigned in only one patient $1 / 197(0.5 \%)$ due to inadequate patient operative documentation. Rotational flaps (Figures 4-6) were the most commonly used type of flaps for the reconstruction of post-excision defects in this study (28.3\%) followed by advancement flaps (27\%) (Figure 1) then forehead flaps (12.1\%) (Figure 3).

\subsection{Distribution of BCC and SCC in Relation to Different Factors}

Regarding sex, number of lesions, treatment modality, occurrence of complications and safety margin status no statistically significance was detected in relation to the histopathological type of NMSCHN either BCC or SCC (after exclusion of other histopathological types) (Table 13).

Table 11. Methods used for closure of the defects following surgical excision of NMSCHN.

\begin{tabular}{ccc}
\hline Type of closure & Number of patients & Percent (\%) \\
\hline Primary closure & 29 & 14.7 \\
Secondry intention & 5 & 2.5 \\
Graft (Figure 7) & 19 & 9.7 \\
Local flap & 126 & 63.9 \\
Free flap & 2 & 1 \\
Graft + local flap & 15 & 7.7 \\
Defect closure was not assigned & 1 & 0.5 \\
Total & 197 & 100
\end{tabular}

Table 12. Types of local flaps used for reconstruction following surgical excision of NMSCHN (Figures 1-7).

\begin{tabular}{ccc}
\hline Type of local flap & Number of patients & Percent (\%) \\
\hline Advancement & 38 & 27 \\
Bilobed (Figure 2) & 3 & 2.1 \\
Cervicofachial & 3 & 2.1 \\
Forehead & 17 & 12.1 \\
Glabellar & 5 & 3.5 \\
Rhomboid & 8 & 5.7 \\
Random & 1 & 0.7 \\
Estlander flap & 2 & 1.4 \\
Rotational & 40 & 28.3 \\
Transposition & 3 & 2.1 \\
V-Y flap & 11 & 7.8 \\
Nasolabial & 4 & 2.8 \\
Karapandzic flap & 6 & 4.3 \\
Total & 141 & 100 \\
\hline
\end{tabular}




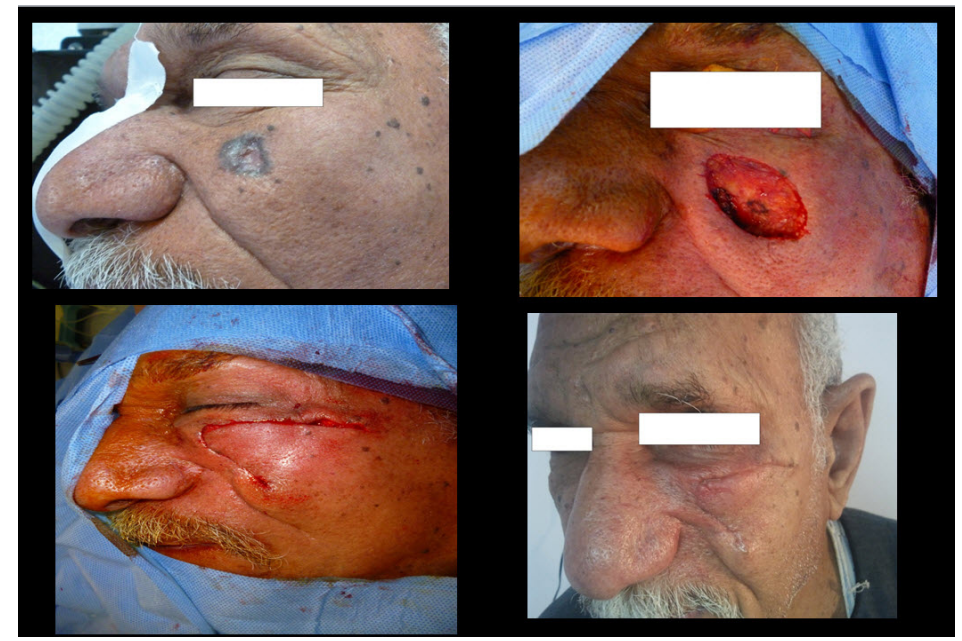

Figure 1. Advancement cheek flap for left cheek BCC.

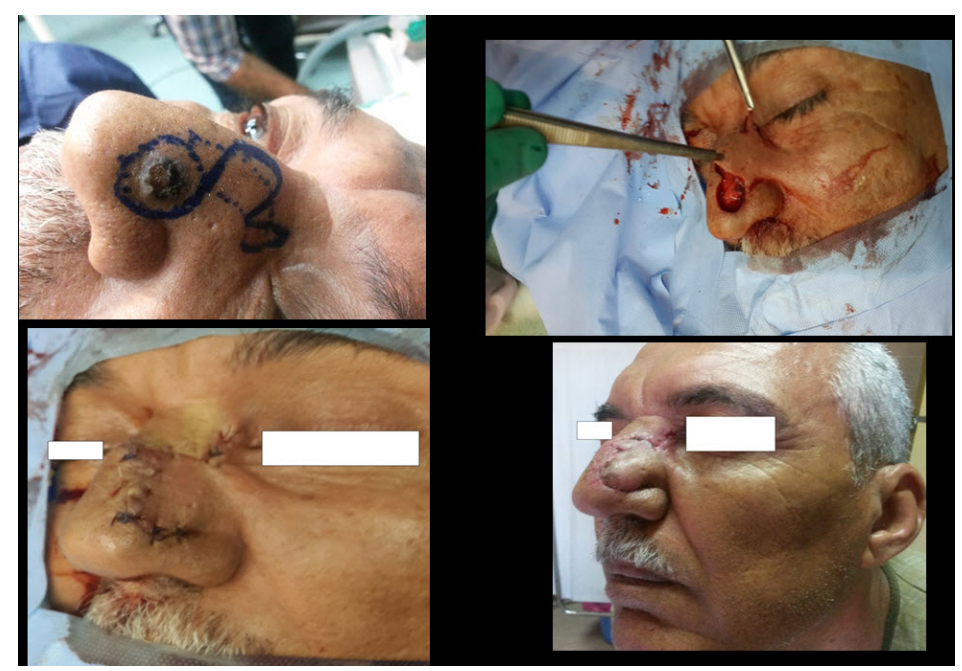

Figure 2. Bilobed flap for BCC of the nose.

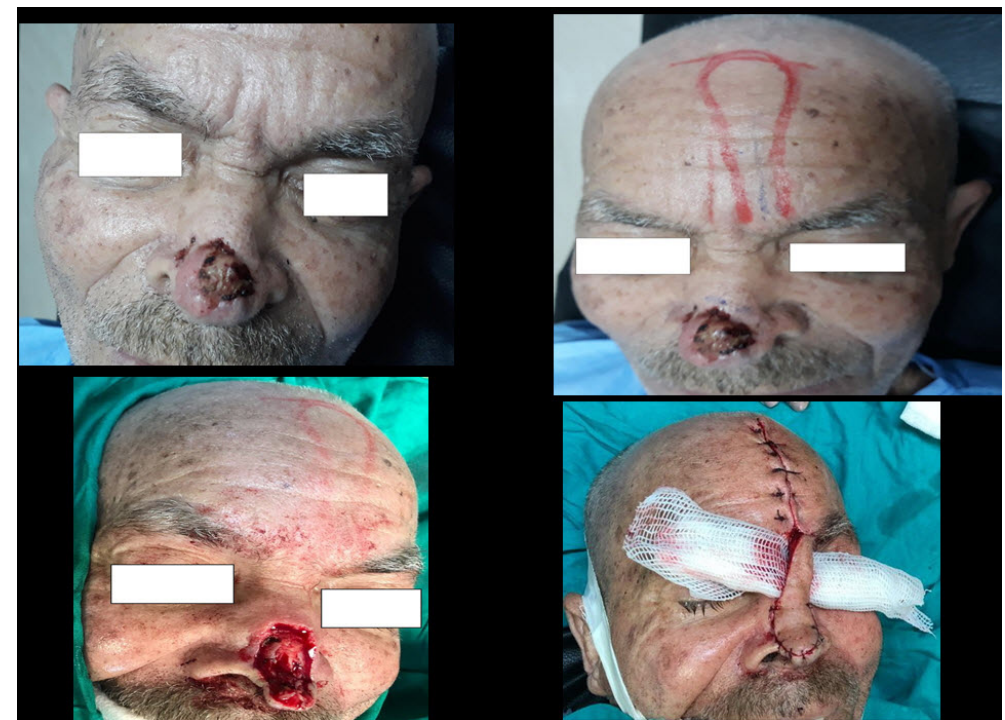

Figure 3. Large SCC of the nose with forehead flap to close the defect. 


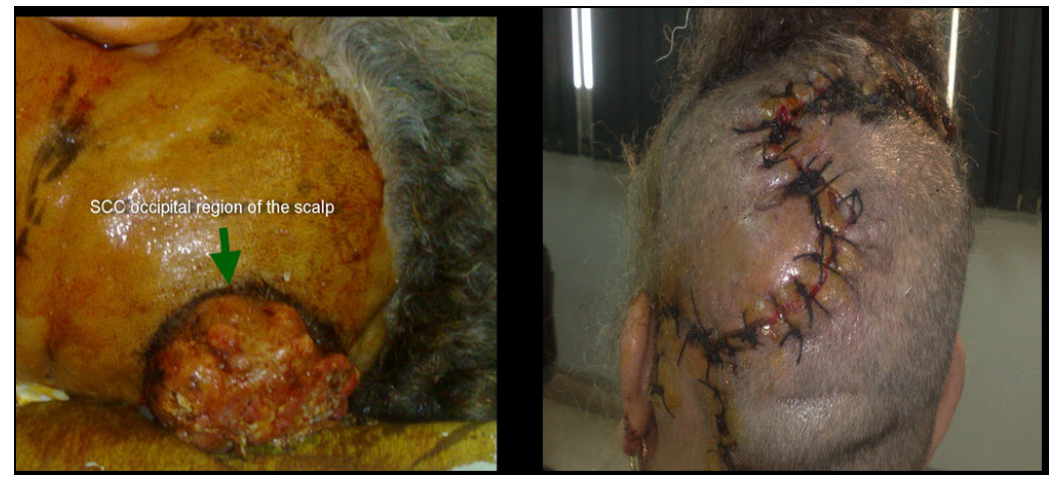

Figure 4. SCC of the occipital region with WLE and closure of the defect with rotational scalp flap.

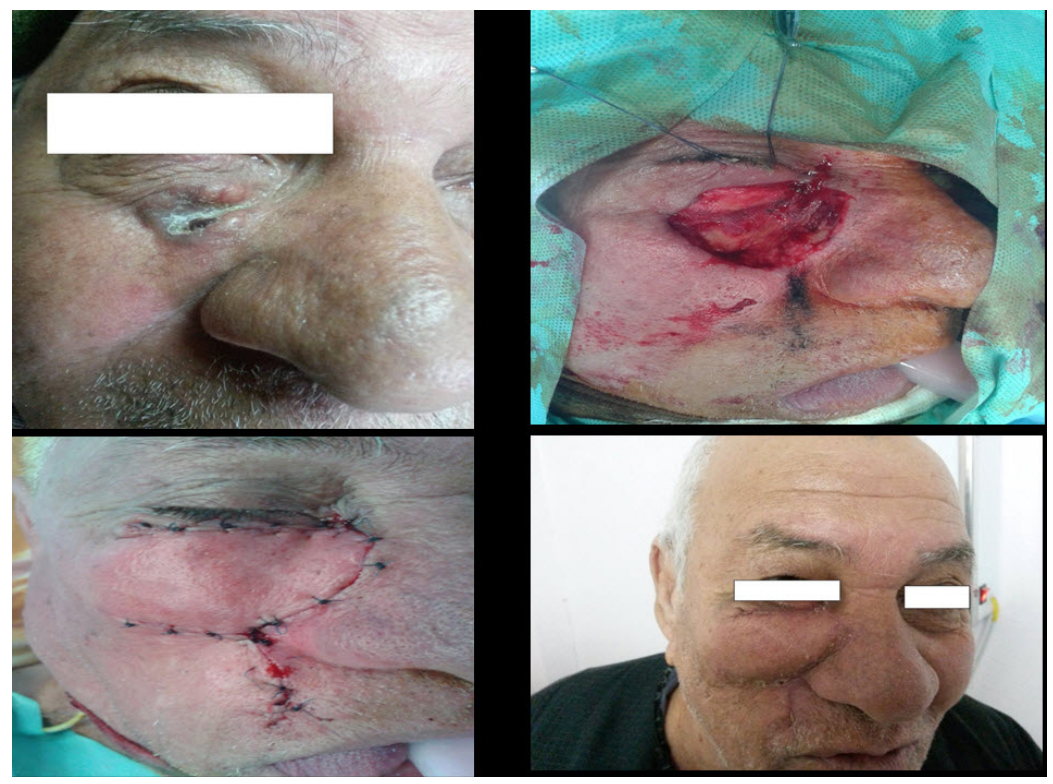

Figure 5. BCC below the right lower eye lid WLE was done with rotational flap.

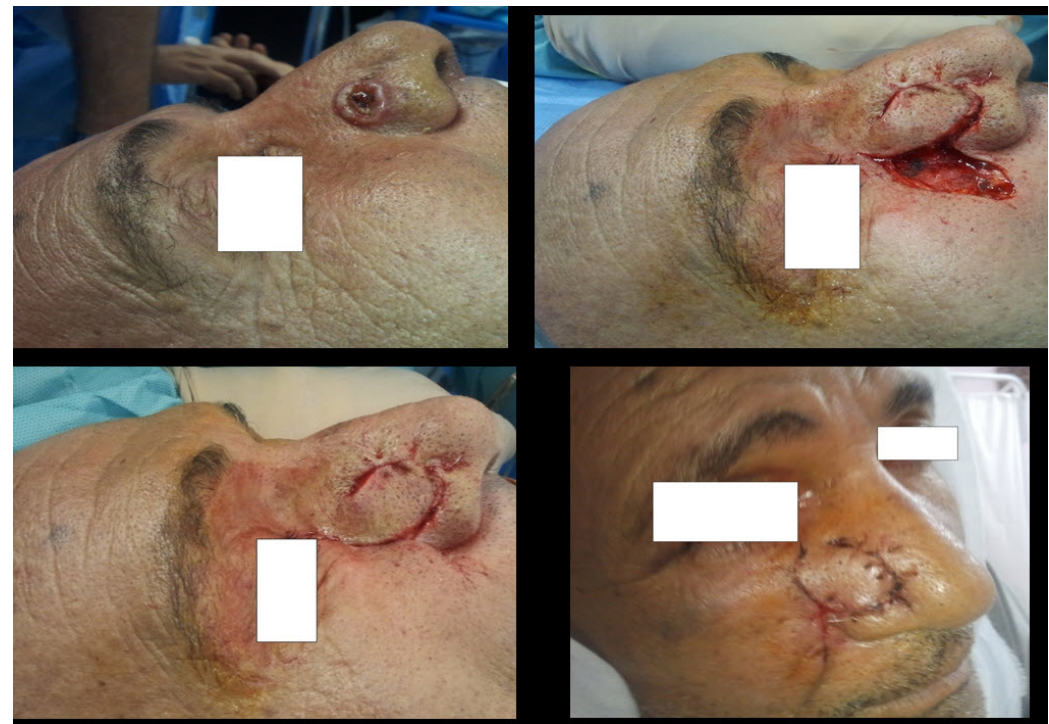

Figure 6. Rotational flap for right nasal BCC. 


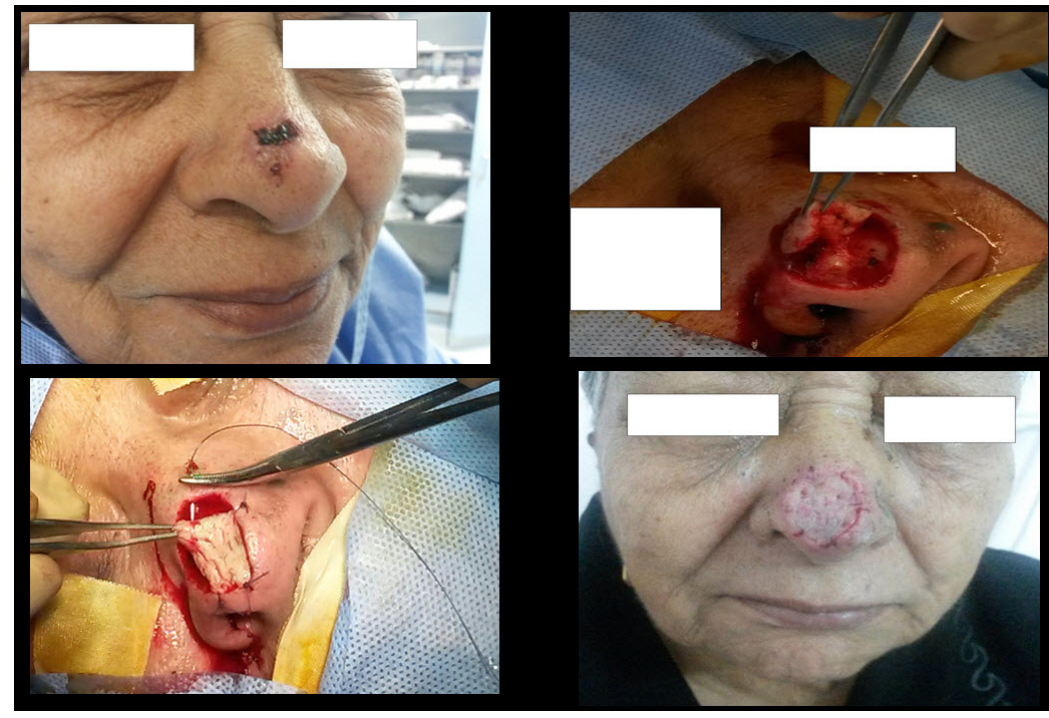

Figure 7. Full thickness (Wolfe) graft from the skin of the arm after WLE of BCC of the nose.

Table 13. Distribution of BCC and SCC in relation to different factors and its significance.

\begin{tabular}{|c|c|c|c|c|}
\hline Factor & $\mathrm{BCC}$ & SCC & Total & p-value \\
\hline \multicolumn{5}{|l|}{ Sex } \\
\hline Male & 79 & 31 & 110 & \multirow{3}{*}{0.031} \\
\hline Female & 64 & 11 & 75 & \\
\hline Total & 143 & 42 & 185 & \\
\hline \multicolumn{5}{|l|}{ Number of lesions } \\
\hline Single & 135 & 41 & 176 & \multirow{3}{*}{0.395} \\
\hline Multiple & 8 & 1 & 9 & \\
\hline Total & 143 & 42 & 185 & \\
\hline \multicolumn{5}{|l|}{ Treatment modality } \\
\hline Surgery & 134 & 39 & 173 & \multirow{5}{*}{0.481} \\
\hline Surgery plus & 6 & 3 & 9 & \\
\hline adjuvant therapy & & & & \\
\hline No interference & 3 & 0 & 3 & \\
\hline Total & 143 & 42 & 185 & \\
\hline Complication & 3 & 2 & 5 & \multirow{3}{*}{0.367} \\
\hline No complication & 136 & 40 & 176 & \\
\hline Total & 139 & 42 & 181 & \\
\hline \multicolumn{5}{|l|}{ Safety margins } \\
\hline Positive & 31 & 5 & 36 & \multirow{4}{*}{0.335} \\
\hline Close & 3 & 1 & 4 & \\
\hline Negative & 105 & 36 & 141 & \\
\hline Total & 139 & 42 & 181 & \\
\hline
\end{tabular}

\subsection{Recurrence (Locoregional/Distant): (Table 14)}

Fifty patients developed loco-regional recurrence. Out of the 50 patients who developed loco-regional recurrences, 45 developed single recurrence and 5 developed repeated recurrences. 9 patients developed regional lymph nodes 
Table 14. Correlation between different factors and recurrence among NMSCHN patients.

\begin{tabular}{|c|c|c|c|c|}
\hline & Recurrence & No recurrence & Total & p-value \\
\hline \multicolumn{5}{|l|}{ Age } \\
\hline$\leq 50$ years & 13 & 18 & 31 & \multirow{3}{*}{0.18} \\
\hline$>50$ years & 37 & 132 & 169 & \\
\hline Total & 50 & 150 & 200 & \\
\hline \multicolumn{5}{|l|}{ Sex } \\
\hline Male & 24 & 93 & 117 & \multirow{3}{*}{0.082} \\
\hline Female & 26 & 57 & 83 & \\
\hline Total & 50 & 147 & 200 & \\
\hline \multicolumn{5}{|l|}{ Number of lesions } \\
\hline Single & 43 & 145 & 188 & \multirow{3}{*}{0.007} \\
\hline Multiple & 7 & 5 & 12 & \\
\hline Total & 50 & 150 & 200 & \\
\hline \multicolumn{5}{|l|}{ T stage } \\
\hline $\mathrm{T} 1$ & 25 & 79 & 104 & \multirow{5}{*}{0.771} \\
\hline $\mathrm{T} 2$ & 19 & 53 & 72 & \\
\hline $\mathrm{T} 3$ & 3 & 13 & 16 & \\
\hline $\mathrm{T} 4$ & 3 & 5 & 8 & \\
\hline Total & 50 & 150 & 200 & \\
\hline \multicolumn{5}{|l|}{ Treatment modality } \\
\hline Surgery & 40 & 146 & 186 & \multirow{3}{*}{0.001} \\
\hline Surgery plus adjuvant therapy & 10 & 1 & 11 & \\
\hline Total & 50 & 147 & 197 & \\
\hline \multicolumn{5}{|l|}{ Pathology } \\
\hline BCC & 30 & 115 & 145 & \multirow{3}{*}{0.25} \\
\hline BSC & 13 & 31 & 44 & \\
\hline Total & 43 & 146 & 189 & \\
\hline \multicolumn{5}{|l|}{ Grade for SCC and BSC } \\
\hline G I & 4 & 10 & 14 & \multirow{4}{*}{0.008} \\
\hline G II & 10 & 23 & 33 & \\
\hline G III & 6 & 1 & 7 & \\
\hline Total & 20 & 34 & 54 & \\
\hline \multicolumn{5}{|l|}{ Safety margins } \\
\hline Positive & 26 & 15 & 41 & \multirow{4}{*}{0.001} \\
\hline Close & 2 & 3 & 5 & \\
\hline Negative & 22 & 128 & 150 & \\
\hline Total & 50 & 146 & 196 & \\
\hline \multicolumn{5}{|l|}{ PO complications } \\
\hline Complications & 4 & 3 & 7 & \multirow{3}{*}{0.051} \\
\hline No complications & 46 & 143 & 189 & \\
\hline Total & 50 & 146 & 196 & \\
\hline
\end{tabular}


metastasis. 6 patients of them were SCC and 3 patients were BSC. Those patients underwent neck dissection. During follow-up 6 SCC, patients developed pulmonary metastasis.

Many independent prognostic factors were found to significantly affect the recurrence rate among patients with NMSCHN. Patients aged more than 50 years old ( $p$-value $=0.18)$, patients with multiple lesions $(p$-value $=0.007)$, patients with high grade of SCC or BSC ( $\mathrm{p}$-value $=0.008)$, patients with positive and close margins $(\mathrm{p}$-value $=0.001)$, patients subjected to surgery + adjuvant therapy ( $\mathrm{p}$-value $=0.001$ ) and patients who showed PO complications ( $\mathrm{p}$-value $=$ 0.051), all those, showed significantly higher recurrence rate in relation to the rest of the study population. Other factors as T stage, sex of patients and BCC vs. BSC pathology didn't show a significant increase in recurrence rate among the study population (Table 14).

\subsection{Disease-Free Survival (DFS): (Table 15)}

Disease free survival ranged from 10.5 to 29.5 months with a median of 20 months. Regarding age, sex, T stage, treatment modality, occurrence of complications, histopathology (BCC vs. SCC) and safety margins; none of those factors showed a statistically significant correlation with Disease-free Survival (DFS).

\section{Discussion}

To our knowledge, this study is by far the largest one in Egypt addressing non-melanoma skin cancer of the head and neck (NMSCHN), regarding the number of patients and the period of follow up which extended up to 84 months. The incidence of non-melanoma skin cancer is still rising worldwide [15], this increase can be, in part, attributed to the increase in the elderly population, in addition, many patients develop more than one non-melanoma skin cancer after the first one [16]. In this study, patients over 50 years old represented $84.5 \%$ of the study population (mean 60, 6 years with the peak incidence in the sixth decade) in whom recurrence rate was significantly higher ( $\mathrm{p}$-value $=0.18$ ), similarly some studies on NMSC detected a peak incidence in the sixth decade of life [10] [11] [17] [18], others in the seventh decade [8] [9] [13] [19] [20]. Male predominance was observed in this study as well as other studies [9] [11] [14] [19] [21], on the other hand, other studies of NMSC showed female predominance [10] [13] [17] [20]. The male sex predilection of skin cancer in Egypt is explained by the fact that men represent the main workforce (outdoor work) with more risk for UV exposure than women [22]. NMSC most commonly occur in the head and neck region [1] [10] [11] [13] [21] [23] [24] [25], and according to this study the scalp, nose and cheek are the most common anatomic sites for the occurrence of NMSCHN, according to Mahmoud et al., 2006 the cheek and nose [10], according to Rhee et al., 2008 the nose, cheek and eyelids [20], according to Al-Zou et al., 2016 the face (NOS), the eyelids and the ear [13], according 
Table 15. Correlation between different factors and DFS among NMSCHN patients.

\begin{tabular}{|c|c|c|c|}
\hline & Number of patients & Median Survival (mo.) & p-value \\
\hline \multicolumn{4}{|l|}{ Age } \\
\hline$\leq 50$ years & 31 & 36 & \multirow{3}{*}{0.177} \\
\hline$>50$ years & 165 & 20 & \\
\hline Total & 196 & 20 & \\
\hline \multicolumn{4}{|l|}{ Sex } \\
\hline Male & 114 & 12 & \multirow{3}{*}{0.4} \\
\hline Female & 82 & 20 & \\
\hline Total & 196 & 20 & \\
\hline \multicolumn{4}{|l|}{ T stage } \\
\hline $\mathrm{T} 1$ & 102 & 20 & \multirow{5}{*}{0.112} \\
\hline $\mathrm{T} 2$ & 71 & 12 & \\
\hline $\mathrm{T} 3$ & 16 & & \\
\hline $\mathrm{T} 4$ & 7 & 48 & \\
\hline Total & 196 & 20 & \\
\hline \multicolumn{4}{|l|}{ Treatment modality } \\
\hline Surgery & 185 & 20 & \multirow{3}{*}{0.398} \\
\hline Surgery plus adjuvant therapy & 11 & 30 & \\
\hline Total & 196 & 20 & \\
\hline \multicolumn{4}{|l|}{ Pathology } \\
\hline $\mathrm{BCC}$ & 139 & 20 & \multirow{3}{*}{0.927} \\
\hline SCC & 42 & 30 & \\
\hline Total & 181 & 20 & \\
\hline \multicolumn{4}{|l|}{ Safety margins } \\
\hline Positive & 41 & 12 & \multirow{4}{*}{0.187} \\
\hline Close & 5 & 6 & \\
\hline Negative & 149 & 36 & \\
\hline Total & 195 & 20 & \\
\hline \multicolumn{4}{|l|}{ PO complications } \\
\hline Complications & 7 & 36 & \multirow{3}{*}{0.507} \\
\hline No complications & 189 & 20 & \\
\hline Total & 196 & 20 & \\
\hline
\end{tabular}

to Marconi et al., 2016 the nose and face [26] and according to Zargaran et al., 2013 the nose, the cheek and the scalp [21] are the most common sites for occurrence of NMSCHN, noting that the nose is commonly affected in all the studies. $\mathrm{T} 1$ lesions represented the main $\mathrm{T}$ stage in this study (52\%) while $\mathrm{T} 2$ represented $36 \%$ of lesions in the study population; this is in agreement with other studies [11] [26]. Nodular type of BCC was by far the most common in this study population (79\%) similarly other studies showed nodular type predominance in BCC [9] [10] [18] [27]. Grade II for SCC and BSC was predominant in our study (61.1\%) while Mahmoud et al., 2006 reported Grade I predomin- 
ance $(46.6 \%)$ [10]. Inspite Alternatives to the surgical management of cutaneous malignancies may be preferred under certain circumstances [11], Surgery remains the main line of treatment for NMSC [28], a recent meta-analysis comparing the different treatment modalities for NMSC demonstrated that surgical excision had superior outcomes when compared to cryotherapy, photodynamic therapy, radiotherapy, 5-flurouracil (5-FU), and imiquimod in terms of complete lesion response, clearance of NMSC, and cumulative recurrence probabilities [29]. 98.5\% of our patients were operated upon as a part of the management strategy. It should be noted that head and neck skin cancers are particularly challenging to treat given the difficulty in determining the amount of tissue that should be excised to provide adequate cancer-free margins with the best functional and cosmetic outcome. In this study, we relied mainly on intra-operative frozen section analysis (IFSA) whenever available, unfortunately, it was not used in all our patients due to unavailability and sometimes due to surgeons' reluctance leading to a high rate of positive margins $(20.9 \%)$ with a significant recurrence rate $(\mathrm{p}=0.001)$. Mohs Micrographic Surgery (MMS) is still not available at our institute, which was not considered a big concern by our team relying on a systemic review by Bath-Hextall et al., 2007 where surgical excision was compared to MMS and demonstrated no difference in 30-month recurrence rates in the treatment of BCC [30]. Similarly, no difference was found in the recurrence risk following treatment of recurrent BCC removed by surgical excision versus MMS [31]. A recent meta-analysis by Lansbury et al., 2013 indicated similar results for cutaneous SCC, signifying no difference between recurrence risk of surgical excision and MMS [32]. Although Bartos and Kullova 2018 stated that BCC and SCC had several clinicopathological differences and should be considered separately [33], our study didn't show any significance regarding the distribution of both BCC and SCC in relation to different factors (Table 13).

Since NMSC only very sporadically leads to metastases, one of the most adverse clinical features of disease is local tumor recurrence. This is a relatively frequent matter in a routine dermatologic practice. According to literature data, local recurrence rates range between $2 \%$ and $4.3 \%$ [34] [35], unfortunately the recurrence rate in this study was high up to $25 \%$ due to several factors including the anatomic sites of the lesions, the size (high risk lesions), the positive margins due to unavailability of IFSA and many patients were operated upon by young surgeons and senior residents.

\section{Conclusion}

NMSCHN lesions should be surgically excised in specialized high volume centers with readily available peripheral margin control and should be operated by senior experienced surgeons.

\section{Conflicts of Interest}

The authors declare no conflicts of interest regarding the publication of this paper. 


\section{References}

[1] Lomas, A., Leonardi-Bee, J. and Bath-Hextall, F. (2012) A Systematic Review of Worldwide Incidence of Non-Melanoma Skin Cancer. British Journal of Dermatology, 166, 1069-1080. https://doi.org/10.1111/j.1365-2133.2012.10830.x

[2] Elshikh, E.A., Anan, I., Ebaid, A.A., Al Gamal, D.A., Hamed, M.M. and Metry, A.B.S. (2015) A Retrospective Cross-Sectional Epidemiological Study. ISPOR 18 th Annual European Congress, 18, A437. https://doi.org/10.1016/j.jval.2015.09.1059

[3] El Khwsky, F., Bedwani, R., D’Avanzo, B., Assaad, S., El Shafei Ali, A., Mokhtar, S. and La Vecchia, C. (1994) Risk Factors for Non-Melanomatous Skin Cancer in Alexandria, Egypt. International Journal of Cancer, 56, 375-378. https://doi.org/10.1002/ijc.2910560314

[4] Ibrahim, A.S., Khaled, H.M., Mikhail, N.N.H., Baraka, H. and Kamel, H. (2014) Cancer Incidence in Egypt: Results of the National Population-Based Cancer Registry Program. Journal of Cancer Epidemiology, 2014, Article ID: 437971.

[5] Batra, R.S. and Kelley, L.C. (2002) Predictors of Extensive Subclinical Spread in Nonmelanoma Skin Cancer Treated with Mohs Micrographic Surgery. Archives of Dermatology, 138, 1043-1051. https://doi.org/10.1001/archderm.138.8.1043

[6] Boyle, K., Newlands, S.D., Wagner Jr., R.F. and Resto, V.A. (2008) Predictors of Reconstruction with Mohs Removal of Nonmelanoma Skin Cancers. Laryngoscope, 118, 975-980. https://doi.org/10.1097/MLG.0b013e31816a8cf2

[7] Rivera, A.E., Webb, J.M. and Cleaver, L.J. (2012) The Webb and Rivera (WAR) Score: A Preoperative Mohs Surgery Assessment Tool. Archives of Dermatology, 148, 206-210. https://doi.org/10.1001/archdermatol.2011.1352

[8] Song, S.S., Goldenberg, A., Ortiz, A., Eimpunth, S., Oganesyan, G. and Jiang, S.I. (2016) Nonmelanoma Skin Cancer with Aggressive Subclinical Extension in Immunosuppressed Patients. JAMA Dermatology, 152, 683-690. https://doi.org/10.1001/jamadermatol.2016.0192

[9] Hussein, M.R. (2005) Skin Cancer in Egypt: A Word in Your Ear. Cancer Biology \& Therapy, 4, 593-595. https://doi.org/10.4161/cbt.4.5.1730

[10] Mahmoud, S.F., Sanad, E.M., Ageena, H.A., Fayed, N.M. and Mohamed, A.E. (2016) A Study of Non-Melanoma Skin Cancer in Benha District, Qalyubiyah Governorate, Egypt. Egyptian Dermatology Online Journal, 2, 12.

[11] Mebed, A.H., Soliman, H.O., Gad, Z.S. and Abdel Hay, R.M. (2010) Multimodality Treatment for Non Melanoma Skin Cancer: A Prospective Study Done on 120 Egyptian Patients. Journal of the Egyptian National Cancer Institute, 22, 49-55.

[12] Elsonbaty, M., Abdal-Rahim, M., Yaseen, O., Fikry, M., Radoan, A. and Abdelaal, M. (2012) Non-Melanoma Skin Carcinoma Versus Skin Carcinoma Complicating Xeroderma Pigmentosa, Egypt. Journal of Plastic, Reconstructive \& Aesthetic Surgery, 36, 125-130.

[13] Al-Zou, A.B., Thabit, M.A., AlSakkaf, K.A. and Basaleem, H.O. (2016) Skin Cancer: Clinico-Pathological Study of 204 Patients in Southern Governorates of Yemen. Asian Pacific Journal of Cancer Prevention, 17, 3195-3199.

[14] Saeid, R., Hosein, R., Mahshid, G., Yousef, K. and Hamid, S. (2015) Changing Trends of Types of Skin Cancer in Iran. Asian Pacific Journal of Cancer Prevention, 16, 4955-4958. https://doi.org/10.7314/APJCP.2015.16.12.4955

[15] National Comprehensive Cancer Network (2011) NCCN Clinical Practice Guidelines in Oncology. Basal Cell and Squamous Cell Skin Cancer. 
[16] Wong, C.S.M., Strange, R.C. and Lear, J.T. (2003) Basal Cell Carcinoma. British Medical Journal, 327, 794-798. https://doi.org/10.1136/bmj.327.7418.794

[17] Rao, J. and Deora, H. (2014) Surgical Excision with Forehead Flap as Single Modality Treatment for Basal Cell Cancer of Central Face: Single Institutional Experience of 50 Cases. Journal of Skin Cancer, 2014, Article ID: 320792. https://doi.org/10.1155/2014/320792

[18] Hassan, M.I. and Hassan, D.A. (2012) Reconstruction after Removal of Basal Cell Carcinoma. Journal of American Science, 8, 42-49.

[19] Igde, M., Yilanci, S., Bali, Y.Y., Unlu, R.E., Duzgun, S. and Pekdemir, I. (2015) Reconstruction of Tissue Defects Developing after Excision of Non-Melanoma Malignant Skin Tumors in Scalp and Forehead Regions. Turkish Neurosurgery, 25, 888-894. https://doi.org/10.5137/1019-5149.JTN.11773-14.0

[20] Rhee, J.S., Davis-Malesevich, M., Logan, B.R., Neuburg, M., Burzynski, M. and Nattinger, A.B. (2008) Behavior Modification and Risk Perception in Patients with Nonmelanoma Skin Cancer. Wisconsin Medical Journal, 107, 62-68.

[21] Zargaran, M., Moghimbeigi, A., Monsef, A.R., Teimourian, H. and Shojaei, S. (2013) A Clinicopathological Survey of Basal Cell Carcinoma in an Iranian Population. Journal of Dentistry of Shiraz University of Medical Sciences, 14, 170-177.

[22] Hussein, M.R., Al-Badaiwy, Z.H. and Guirguis, M.N. (2004) Analysis of p53 and bcl-2 Protein Expression in the Nontumorigenic, Pretumorigenic, and Tumorigenic Keratinocytic Hyperproliferative Lesions. Journal of Cutaneous Pathology, 31, 643-651. https://doi.org/10.1111/j.0303-6987.2004.00244.x

[23] Robson, M.C., Zachary, L.S., Schmidt, D.R., Faibisoff, B. and Hekmatpanah, J. (1989) Reconstruction of Large Cranial Defects in the Presence of Heavy Radiation Damage and Infection Utilizing Tissue Transferred by Microvascular Anastomoses. Plastic and Reconstructive Surgery, 83, 438-442. https://doi.org/10.1097/00006534-198903000-00004

[24] Rogers, H.W., Weinstock, M.A., Harris, A.R., et al. (2010) Incidence Estimate of Nonmelanoma Skin Cancer in the United States, 2006. Archives of Dermatology, 146, 283-287. https://doi.org/10.1001/archdermatol.2010.19

[25] Alam, M. and Ratner, D. (2001) Cutaneous squamous-Cell Carcinoma. The New England Journal of Medicine, 344, 975-983. https://doi.org/10.1056/NEJM200103293441306

[26] Marconi, D.G., Resende, B.D.C., Rauber, E., Soares, P.D.C., Fernandes, J.M., Mehta, N., Carvalho, A.L., Kupelian, P.A. and Chen, A. (2016) Head and Neck Non-Melanoma Skin Cancer Treated By Superficial X-Ray Therapy: An Analysis of 1021 Cases. PLoS ONE, 11, e0156544. https://doi.org/10.1371/journal.pone.0156544

[27] Schnebelen, A.M., Gardner, J.M. and Shalin, S.C. (2016) Margin Status in Shave Biopsies of Nonmelanoma Skin Cancers Is It Worth Reporting? Archives of Pathology \& Laboratory Medicine, 140, 678-681. https://doi.org/10.5858/arpa.2015-0313-OA

[28] Gualdi, G., Monari, P., Apalla, Z. and Lallas, A. (2015) Surgical Treatment of Basal Cell Carcinoma and Squamous Cell Carcinoma. Giornale Italiano di Dermatologia e Venereologia, 150, 435-447.

[29] Lv, R. and Sun, Q. (2017) A Network Meta-Analysis of Non-Melanoma Skin Cancer (NMSC) Treatments: Efficacy and Safety Assessment. Journal of Cellular Biochemistry, 118, 3686-3695. https://doi.org/10.1002/jcb.26015

[30] Bath-Hextall, F.J., Perkins, W., Bong, J. and Williams, H.C. (2007) Interventions for Basal Cell Carcinoma of the Skin. Cochrane Database of Systematic Reviews. 
https://doi.org/10.1002/14651858.CD003412.pub2

[31] Smeets, N.W., Krekels, G.A., Ostertag, J.U., Essers, B.A., Dirksen, C.D., Nieman, F.H. and Neuman, H.A. (2004) Surgical Excision vs. Mohs' Micrographic Surgery for Basal-Cell Carcinoma of the Face: Randomised Controlled Trial. The Lancet, 364, 1766-1772. https://doi.org/10.1016/S0140-6736(04)17399-6

[32] Lansbury, L., Bath-Hextall, F., Perkins, W., Stanton, W. and Leonardi-Bee, J. (2013) Interventions for Nonmetastatic Squamous Cell Carcinoma of the Skin: Systematic Review and Pooled Analysis of Observational Studies. British Medical Journal, 347, f6153. https://doi.org/10.1136/bmj.f6153

[33] Bartoš, V. and Kullová, M. (2018) Non-Melanoma Skin Cancer: A Clinicopathological Study of Patients with Basal Cell Carcinoma and Squamous Cell Carcinoma. Klinicka Onkologie Journal, 31, 40-45. https://doi.org/10.14735/amko201840

[34] Chren, M.M., Torres, J.S., Stuart, S.E., et al. (2011) Recurrence after Treatment of Nonmelanoma Skin Cancer: A Prospective Cohort Study. Archives of Dermatology, 147, 540-546. https://doi.org/10.1001/archdermatol.2011.109

[35] Lee, J.S., Yi, J.H., Yun, S.K., Kim, H.-U. and Ihm, C.-W. (2010) Clinicohistopathological Study of Recurrent Basal Cell Carcinomas after Surgical Excision. Korean Journal of Dermatology, 48, 453-459. 